\title{
Fertility Preservation Counselling for Women With Endometriosis: A European Online Survey
}

\author{
Nicole Sänger \\ University Bonn \\ Marco Menabrito \\ Gedeon Richter / Preglem s.a. \\ Atillio Di Spiezo Di Spiezo Sardo \\ University Naples \\ Josep Estadella \\ University Barcelona \\ Jasper Verguts ( $\sim$ jasper.verguts@jessazh.be ) \\ Jessa Hospital https://orcid.org/0000-0002-2185-1213
}

\section{Research}

Keywords: endometriosis, endometrioma, surgery, assisted reproductive technology (ART), ovarian reserve, female infertility, fertility preservation, cryopreservation, oocyte, ovarian tissue

Posted Date: October 27th, 2021

DOI: https://doi.org/10.21203/rs.3.rs-966804/v1

License: (c) (1) This work is licensed under a Creative Commons Attribution 4.0 International License. Read Full License 


\section{Abstract}

Background. Endometriosis is a common cause for infertility. Decreased ovarian reserve due to pathology or surgical management can reduce the chances of natural pregnancy and limit the effectiveness of controlled ovarian stimulation during fertility treatment. Cryopreservation of oocytes or ovarian cortex prior to surgery or before loss of follicular capital are strategies to preserve fecundity.

Methods: An online survey was sent to reproductive specialists and gynaecological surgeons representing major centers of reproductive medicine in Europe to investigate current fertility preservation practices for endometriosis patients.

Results. Of 58 responses, 45 (77.6\%) in 11/13 countries reported the existence of endometriosis management guidelines, of which $37 / 45(82.2 \%)$ included treatment recommendations for infertile patients. Most centers (51.7\%) reserved fertility counselling for severe endometriosis (large endometriomas with or without deep endometriosis) while $15.5 \%$ of centers did not offer fertility preservation for endometriosis.

Conclusions. To address non-uniformity in available guidelines and the diversity in fertility preservation practices, we propose an algorithm for managing patients with severe endometriosis most likely to be impacted by reduced ovarian reserve. Improved awareness about the possibilities of fertility preservation and clear communication between gynaecological surgeons and reproductive medicine specialists is mandatory to address the unmet clinical need of preventing infertility in women with endometriosis.

\section{Plain English Summary}

Women with endometriosis may have a decreased chance of pregnancy where cryopreservation could be beneficial to maintain fecundity. An online survey involving reproductive specialists and gynaecological surgeons was carried out to assess the current situation in Europe regarding the management of women with endometriosis seeking fertility. Within the 58 respondents there was a diversity of treatment options. Although some guidelines exist, there is clearly a lack of uniformity. One in six centers did not offer any fertility preservation in women with endometriosis. We propose an algorithm that could help women with severe endometriosis to maintain fertility. As awareness on this topic would increase, more women could benefit from an improved cooperation between gynaecological surgeons and fertility specialists.

\section{Background}

Fertility preservation of oocytes and embryos has been used for several years. Its efficacy and safety have been demonstrated not only in women requiring gonadotoxic therapies due to malignant diseases, but also in other circumstances that threaten the ovarian reserve, such as endometriosis [1-4].

Endometriosis is a common chronic inflammatory condition of the pelvis, which can lead to dysmenorrhoea, chronic pelvic pain and infertility. It is an oestrogen-dependent disease that affects up to $10 \%$ of women during their reproductive life. Fertility issues are present in approximately $30-50 \%$ of endometriosis patients, with both pathologic and iatrogenic causes $[5,6]$.

Pathologic causes of infertility associated with endometriosis include dysfunctional uterine and tubular peristaltic motility, chronic intraperitoneal inflammation, disturbed folliculogenesis, luteinized unruptured follicles, luteal phase defects, progesterone resistance and anti-endometrial antibodies [7]. With large endometriomas, loss of follicular 
density can occur secondary to stretching of the ovarian cortex and additional gonadotoxic insult can result from iron uptake from cells near the endometrioma. Local inflammation leads to fibrosis and loss of cortex-specific stroma and might be associated with reduced vascularisation and increased oxidative stress, resulting in atresia, "burn-out" of the ovary and a reduced follicular count [8-11]. Surgical management of endometriosis can also have a detrimental effect on ovarian reserve $[12,13]$. The surgical removal of endometriotic lesions may cause iatrogenic adnexal or follicular damage when removing ovarian endometriomas and pelvic adhesions, even in the hands of highly skilled surgeons [14].

Thus, while fertility treatment is frequently sought among women with endometriosis, the outcomes of assisted reproductive techniques (ART) may be impaired due to fewer oocytes and poor oocyte quality. Indeed, there is a negative correlation between the size of the endometriomas and anti-Müllerian hormone (AMH) levels, and patients with bilateral endometriomas have a lower $\mathrm{AMH}$ than those with unilateral endometriomas [15]. These factors can affect the ovarian response to stimulation in ART, leading to use of increased follicle-stimulating hormone (FSH) doses [16-18].

These issues highlight a need for fertility preservation strategies to protect follicular capital in women with endometriosis before the condition advances or surgical treatment compromises ovarian function. Cryopreservation of fertilized oocytes for use in later embryo transfer cycles shows comparable rates of fertilization, embryo development and pregnancy rates to freshly transferred embryos in patients with endometriosis $[4,19,20]$. Cryopreservation of ovarian cortex, first described by Donnez et al (2004) [21] is another technique that has become increasingly accepted for fertility preservation and endorsed by the American Society for Reproductive Medicine (ASRM) [22].

In women with ovarian endometriomas, pre-operative assessment of AMH and antral follicular count (AFC) are relevant before a planned surgical treatment, as women with advanced stage endometriosis tend to have a lower serum AMH levels and because postoperative infertility is more likely to occur in older patients with a lower level of serum AMH per se [23]. A negative effect of age, number of vitrified oocytes and oocyte survival on the cumulative life-birth-rate was recently confirmed in a large series of endometriosis patients that underwent fertility preservation $[24,25]$. Results from this group indicate that 20 or more vitrified oocytes would be needed to achieve at least one life birth after fertility preservation in an endometriosis patient [20], a goal that might be reachable in younger patients within one or two controlled ovarian stimulations. In women older than 35 years and perhaps for surgeries that have already taken place due to endometriosis cysts or implants, this number would be impossible to attain [24]. Therefore, fertility preservation counselling should be offered before endometriosis surgery in some conditions, when the risks of deleterious effect on the ovarian reserve are obvious. Depending on the disease stage, it could also be advisable to perform surgical excision of endometriomas before ovarian stimulation for fertility preservation [26]. Despite the known potential risks of impaired fertility with endometriosis, not all physicians take fertility preservation into account when planning therapeutic options as no clear clinical guidelines for endometriosis and fertility preservation exist in most countries. A review of national and international guidelines on diagnosis and therapy of endometriosis shows contradicting recommendations on whether IVF or surgery should be performed as the first approach in endometriosis patients, and fertility preservation does not have a significant place in the guidelines, even in patients with severe endometriosis [27].

Whether a patient receives fertility counselling may depend on the type (surgeon or a fertility specialist) and expertise of the physician to whom she is first referred. A published debate among surgical gynaecologists and reproductive medicine specialists illustrates that the approach to managing endometriosis patients varies enormously [26]. The surgeons' viewpoint is that diagnostic laparoscopy will confirm an early diagnosis, reduce pain and improves the 
natural conception rate, enabling the patient to receive optimal further treatment after a pregnancy. Reproductive medicine specialists advocate IVF as the initial strategy because it will shorten the time to pregnancy and avoid any adverse influence of surgery on the ovarian reserve. Alongside these opposing approaches, the possibility of maintaining fertility by cryopreservation of fertilized or unfertilized oocytes was mentioned by only one of the panellists in this debate [26].

Likewise, communications between treatment centres and patients about options for fertility preservation are lacking, since not all institutions offer elective fertility preservation or have protocols to guide patients for fertility counselling [28]. For young patients however the feasibility of a systematic proposal of fertility preservation by oocyte cryopreservation has already been demonstrated and an oocyte accumulation strategy was proposed to enhance further pregnancy chances [29-31].

We therefore conducted a European survey to investigate the existence of local guidelines regarding endometriosis surgery and fertility preservation, to evaluate if centres/hospitals are offering this possibility, and if so, which techniques are used, and how these are performed.

\section{Materials And Methods}

A 19-item questionnaire (see Appendix A) was developed, agreed, and tested among all the authors. It was hosted on an online survey platform (SurveyMonkey). The questions included either multiple-choice or single-response answers. The questionnaire was sent to gynaecological surgeons and fertility specialists through the ORBIS network, an international collaborative group of gynaecologists specialized in diseases such as fibroids and endometriosis that can impair infertility.

The questionnaire was distributed between December 2019 and March 2020 and again between January 2021 until March 2021 to increase the response-rate. It was distributed by email to major centres of reproductive medicine across Europe and directly to medical colleagues. It was also advertised on social media including Facebook, Twitter and Instagram, and included in newsletters of gynaecological and fertility centres/ hospitals.

We planned to have at least one response from every country to provide a European overview on the current situation.

\section{Results}

A total of 61 responses were collected from 13 European countries. Three were excluded due to double entries from the same institution. Thus, responses from a total of 58 European fertility centres/hospitals (30 public, 22 private and 6 are not available) were evaluated, of which 18 were university hospitals and/or fertility centres with a high number of IVF cycles ( $>500$ cycles, $n=17 ;>1000$ cycles: $n=14$; Figure 1 ). Seven centres do not perform any ART but offer endometriosis treatments and surgery.

\subsection{Endometriosis guidelines}

Of particular interest was whether a national endometriosis guideline existed in the countries that responded, and whether such guidelines included treatment options both for infertile patients and for fertility preservation. The majority of respondents ( $n=45,77.6 \%$ ) affirmed an existing guideline for endometriosis, including centres in Germany, Spain, Italy, Denmark, the Netherlands and the UK. Thirteen (22.4\%) respondents stated there were no national guidelines at all on endometriosis; these included centres in Belgium, France, Portugal, Austria, Switzerland, Finland and Sweden, though Swedish national guidelines were published in June 2020 [32], which was after our first survey 
period. Several of these countries, however, reported contradictory answers towards the availability of an endometriosis guideline (Figure 2), suggesting that even where guidelines are available, they are not followed universally. Of respondents who were aware of a national guideline for endometriosis, 37/45 (82.2\%) reported that treatment recommendations for infertile patients were included.

\subsection{Fertility preservation in endometriosis patients}

Since treatment using ART is common in infertile patients, we focused our questions in this study on fertility preservation, especially in patients with severe stage III and IV endometriosis and the desire to have children. Overall, $84.5 \%$ of centres offered elective fertility preservation to some or all women with endometriosis; this was to all patients with endometriosis (32.8\%), only patients with large endometriomas (29.3\%), or in some centres, only where large endometrioma was combined with deep infiltrating endometriosis (22.4\%). Only $15.5 \%$ of centres did not offer any treatment for fertility preservation.

Among centres that offered fertility preservation for endometriosis patients, multiple criteria were used to support this decision, the most common being age of the patient (81.0\%) and a reduced ovarian reserve (75.9\%). "Previous uni- or bilateral endometriomas with or without surgery" (55.2\%), "delayed fertility wish" (55.2\%) and "risk of losing time by surgery and recovery" (46.6\%) were also important factors. Six centres did not offer fertility preservation in case of low ovarian reserve parameters or due to the absence of standard operation procedures for fertility preservation.

In the case of large endometriomas ( $\geq 4 \mathrm{~cm}$ ), $50.0 \%$ of centres reported that they would perform medical or surgical interventions before ovarian stimulation to facilitate oocyte pick-up, usually laparoscopic cystectomy or ablation (depending on size and thickness of the cystic wall). One centre uses progestin only ahead of controlled ovarian stimulation; two centres use gonadotropin-releasing hormone $(\mathrm{GnRH})$ agonists only; and two centres offer first-line $\mathrm{GnRH}$ agonists followed by laparoscopic surgery. In respondent centres in France, an intraoperative treatment with ethanol is used in cases of large endometrioma, and hormonal treatment combined with antibiotics is used in centres from Austria and the United Kingdom.

In France, an intraoperative treatment with ethanol is used in cases of large endometrioma, and hormonal treatment combined with antibiotics is used in Austria and the United Kingdom.

Nearly all respondents (89.3\%) confirmed that they measured ovarian reserve with $\mathrm{AMH}, \mathrm{AFC}$ and/or FSH before planning an individual treatment.

\subsection{Therapeutic options in fertility preservation}

The preferred protocol for fertility preservation in endometriosis among responding centres is cryopreservation of unfertilized oocytes (31 centres, 53.4\%) (Figure 3). For cryopreservation, most centres routinely perform vitrification (84.5\%), while the others use the slow freezing method.

The difference among countries in the permitted storage period for cryopreserved embryos or unfertilized egg cells is remarkable. While there is reportedly no time limit in most respondent centres (e.g., Austria, Germany, and Italy), storage time is limited in centres in Portugal (10 years), Belgium (until maternal age 43 years), Sweden (10 years), France and the United Kingdom. As for responses to other questions, there were some discrepancies from different centres in the same country. In Belgium, a storage period of 5 years was indicated by one centre, and a storage time to age 43 years by another, where the two answers may not be mutually exclusive. Similarly, in the United Kingdom, 
responses suggested there is a maximum storage period of 10 years up to a maximum age of 55 . In France, the centres provided contradicting information regarding restrictions.

Centres from Belgium, Finland, the Netherlands, Portugal and Spain all reported an age limit for performing embryo transfer, which varies between 43 and 55 years. There was no reported age restriction for embryo transfer in centres from Austria, France, Germany and Italy.

The most frequently used protocol for controlled ovarian stimulation before oocyte pick-up and storage was the antagonist protocol, used in $44.8 \%$ of the fertility centres. Interestingly, only 5 centres (8.6\%) worked with the ultralong protocol using GnRH agonists, 6 centres (10.3\%) performed the classic long protocol and only one centre specified a natural cycle as their preferred approach. However, $34.5 \%$ of all fertility centres indicated individual therapy planning, so that the use of $\mathrm{GnRH}$ agonists might be part of the protocol, if required.

\subsection{Post-surgery waiting time}

Since evidence is lacking about the optimal waiting time between endometriosis surgery and fertility treatment or pregnancy, we were also interested in the opinion of the respondents about this topic. Half of the respondents (28 centres, $48.3 \%$ ) allowed pregnancy immediately after surgery, 24 centres (41.4\%) would recommend waiting for at least three months and 6 centres would recommend waiting up to 6 months before allowing pregnancy.

\subsection{Medical treatment between surgery and pregnancy}

Nearly eighty-three percent of respondents would consider offering drug therapy after surgery for endometriosis, usually oral contraceptives $(62.7 \%)$ or $\mathrm{GnRH}$-agonists $(20.1 \%)$. The remaining $17.2 \%$ of respondents answered there is no need or indication for adjuvant therapy after surgery. Where oral contraceptives were advised, the mostpreferred were progestin-only-pills ( $41.4 \%$ of all respondents) or combined oral contraceptives with a long cycle regime (44.8\%).

\subsection{Economic costs}

The last question looked at cost coverage of fertility preservation as part of the national system or by health insurance companies. Thirty-nine respondents (67.2\%) reported that no coverage for fertility preservation is available. Countries where some form of reimbursement exist are Italy, France, Finland and Sweden. In Germany, public funding was approved in May 2019, to cover fertility preservation by cryopreservation of fertilized or unfertilized oocytes, but not for ovarian cortex storage; however, the guidelines that determine the amount of funding that will be covered and for which type of patient is still to be agreed. Once more, we obtained conflicting information from different centres within Belgium, Spain and the United Kingdom.

\section{Discussion}

To the best of our knowledge, this is the first European survey on the availability and practice of fertility preservation in women with endometriosis. Many studies have addressed the issue of decreased fertility associated with endometriosis, but no uniform guidelines are in place for the implementation of fertility preservation in clinical practice. Moreover, where guidelines do exist, they are not consistently recognised. While some centres adhere to local or national guidelines, it was evident from discrepant responses to some questions among centres from the same countries that there is inconsistency in practices relating to management of infertility associated with endometriosis and provision of fertility preservation, and in limitations placed on them. A more uniform guideline is needed that is based on the available clinical evidence and is relevant for women across Europe. Every experienced 
gynaecologist is aware that both the condition of endometriosis and surgical treatments to manage it can significantly impair ovarian reserve. Although thousands of women across Europe are treated for endometriosis every day, the option of maintaining fertility plays a subordinate role. In addition to the organic changes in the ovary that occur especially in stage III and IV endometriosis, the advancing age at which many women now choose to try for a first pregnancy further increases the difficulty of achieving a successful reproductive outcome. Collectively, therefore it is surprizing that there are few clear and uniform guidelines that anticipate the risk of declining fertility and provide timely treatment recommendations for preserving fertility.

This survey shows there is a need for guidelines to encourage fertility preservation in women with endometriosis before loss of ovarian reserve, with a focus on management of patients with bilateral endometriomas or those requiring multiple surgical interventions, in whom ovarian impact is greatest. Factors such as age, AMH and AFC, are of paramount importance to determine the most appropriate procedure and timing for the best chances of success. Undoubtedly, when considering the possibility of fertility preservation before planning endometriosis surgery, the younger the patient the better the results will be in terms of, for example, oocyte survival and cumulative live-birth-rate $[20,24]$. The cost-effectiveness of treatment and the calculation of costs by the health insurance company must not be disregarded. Two-thirds of respondents in the survey reported that there was no financial coverage for the provision of fertility preservation services in their country, although there were some conflicting responses on this point.

With around 180 million women affected with endometriosis worldwide [33], a substantial effort would need to be made to implement a new guideline effectively, including changes in routine patient counselling pathways. A clear communication between gynaecologists performing surgery and reproductive medicine specialists is mandatory to increase the patient's likelihood of accessing services and having a baby. It is also important to remember that reproductive medicine has its limits, and can only help efficiently against the disruption of folliculogenesis caused by endometriosis, reduced sperm transport, chronic inflammation or even implantation defects due to decreased embryo receptivity [34-36].

The present survey was intended to provide an insight into the extent to which fertility preservation plays a role in the management of endometriosis patients in clinical practice and whether there are significant differences across Europe. However, the study is limited in the relatively small number of respondents and the lack of representation of some countries and it has no claim to provide a complete picture of endometriosis therapy in individual countries. Two rounds of the survey were necessary to attain a valid response-rate (28 responses the first round and 33 on the second. The fact that some centres disregarded the survey might suggest a general disinterest in this issue, which for women with endometriosis who struggle with infertility may seem discouraging. As indeed few centers in our survey follow guidelines regarding endometriosis and fertility preservation, many other centers will also have no interest and no guidelines and thus no respond to this survey. This is yet another reason why this survey is important for women with endometriosis. However, there are many factors that could influence the response rate to a survey of this type, other than actual interest in the topic.

In view of the responses in the first and second round however, we found little or no differences, indicating that the responses obtained provided good representation of the fertility preservation practices in endometriosis across Europe. The high representation of Germany in the study - one-third of all responses - is striking, although it was not considered to be a confounding factor as the survey was designed mostly to evaluate local practices rather than to provide country-level responses. 
The results of the survey revealed a heterogeneity across centres in Europe in counselling on fertility preservation and treating patients of reproductive age suffering from endometriosis. This may be due to differing or absent national guidelines, as well as a lack of standardized procedures and cooperation between surgical centres and fertility centres. It was notable that in some cases, specialists were unaware of the existence of guidelines available in their country.

In fact, over the past 10 years, guidelines for fertility preservation or diagnosis and treatment of endometriosis have been published in almost all European societies for gynaecology and obstetrics, and include recommendations from ESHRE, NICE, DGGG/ AWMF, SEF, CNGOF and SIGO, alongside globally recognised guidelines from ACOG, FIGO and WES (Table 1). In the guidelines for fertility preservation, no information is given explicitly for endometriosis patients and, conversely, the endometriosis recommendations rarely contain a clear statement regarding counselling and/or implementation of fertility maintenance. Seven out of 15 societies recommend the regular determination of the fertility parameters $\mathrm{AMH}$ and $\mathrm{AFC}$ and provide medical and surgical therapeutic options for those wishing to conceive $(9 / 15)$. More than half of the published statements also consider that advice should be given on the potential impairment of the ovarian reserve (8/15), but without providing precise information about scenarios where fertilitypreserving options such as freezing of oocytes or ovarian tissue is indicated. Indeed, the topic was intensively discussed for the first time in a plenary session at the 6th Biennial World Congress of the International Society for Fertility Preservation (ISFP) in New York, 2019, confirming the importance and increasing recognition of the place of fertility preservation in women with benign diseases such as endometriosis [37]. 
Table 1

Available international guidelines and recommendations on endometriosis, infertility and fertility preservation.

\begin{tabular}{|c|c|c|c|c|c|c|}
\hline $\begin{array}{l}\text { Country/regional } \\
\text { guideline } \\
\text { [reference] }\end{array}$ & Year & $\begin{array}{l}\text { Institute/ } \\
\text { Group/ } \\
\text { Society }\end{array}$ & $\begin{array}{l}\text { Measurement } \\
\text { of fertility } \\
\text { parameters } \\
\text { prior to } \\
\text { surgery? }\end{array}$ & $\begin{array}{l}\text { Recommenda- } \\
\text { tions for } \\
\text { infertile } \\
\text { patients? }\end{array}$ & $\begin{array}{l}\text { Recommenda- } \\
\text { tions on } \\
\text { fertility } \\
\text { preservation? }\end{array}$ & $\begin{array}{l}\text { Surgery prior to } \\
\text { IVF? }\end{array}$ \\
\hline $\begin{array}{l}\text { USA: } \\
\text { Endometriosis } \\
\text { [38] }\end{array}$ & 2010 & ACOG & No & No & No & IVF not listed \\
\hline $\begin{array}{l}\text { Canada : } \\
\text { Endometriosis } \\
\text { [39] }\end{array}$ & 2010 & SOGC & No & Yes & No & $\begin{array}{l}\text { In case of pain } \\
\text { and } \\
\text { endometriomas } \\
>3 \mathrm{~cm}\end{array}$ \\
\hline $\begin{array}{l}\text { Europe: } \\
\text { Endometriosis } \\
\text { [40] }\end{array}$ & 2014 & ESHRE & No & Yes & No & $\begin{array}{l}\text { In case of pain } \\
\text { and } \\
\text { endometriomas } \\
>3 \mathrm{~cm}\end{array}$ \\
\hline $\begin{array}{l}\text { Europe: Female } \\
\text { fertility } \\
\text { preservation [41] }\end{array}$ & 2020 & ESHRE & Yes & No & Yes & $\begin{array}{l}\text { No, as diseases } \\
\text { are not listed } \\
\text { individually }\end{array}$ \\
\hline $\begin{array}{l}\text { International: } \\
\text { Endometriosis }\end{array}$ & 2016 & FIGO & No & Yes & No & $\begin{array}{l}\text { In case of pain } \\
\text { and }\end{array}$ \\
\hline $\begin{array}{l}\text { pain and } \\
\text { infertility [42] }\end{array}$ & & & & & & $\begin{array}{l}\text { endometriomas } \\
>3-4 \mathrm{~cm}\end{array}$ \\
\hline $\begin{array}{l}\text { International: } \\
\text { Endometriosis } \\
\text { [43] }\end{array}$ & 2017 & WES & No & No & No & No \\
\hline $\begin{array}{l}\text { France: } \\
\text { Endometriosis } \\
\text { [44] }\end{array}$ & 2018 & CNGOF & Yes & Yes & Yes & No \\
\hline $\begin{array}{l}\text { Germany: } \\
\text { Endometriosis } \\
\text { [45] }\end{array}$ & 2020 & $\begin{array}{l}\text { DGGG/ } \\
\text { AWMF }\end{array}$ & No & No & No & No \\
\hline $\begin{array}{l}\text { Germany: } \\
\text { Fertility } \\
\text { preservation [46] }\end{array}$ & 2017 & $\begin{array}{l}\text { DGGG/ } \\
\text { AWMF }\end{array}$ & No & No & No & $\begin{array}{l}\text { Endometriosis } \\
\text { not listed in } \\
\text { this guideline }\end{array}$ \\
\hline $\begin{array}{l}\text { Germany, } \\
\text { Switzerland, } \\
\text { Austria: Fertility } \\
\text { preservation [47] }\end{array}$ & 2020 & $\begin{array}{l}\text { Ferti- } \\
\text { PROTEKT }\end{array}$ & Yes & Yes & Yes & No \\
\hline $\begin{array}{l}\text { Italy: } \\
\text { Endometriosis } \\
\text { [48] }\end{array}$ & 2018 & SIGO & No & Yes & Yes & $\begin{array}{l}\text { Yes in case of } \\
\text { pain but not } \\
\text { obligatory }\end{array}$ \\
\hline
\end{tabular}




\begin{tabular}{|c|c|c|c|c|c|c|}
\hline $\begin{array}{l}\text { Country/regional } \\
\text { guideline } \\
\text { [reference] }\end{array}$ & Year & $\begin{array}{l}\text { Institute/ } \\
\text { Group/ } \\
\text { Society }\end{array}$ & $\begin{array}{l}\text { Measurement } \\
\text { of fertility } \\
\text { parameters } \\
\text { prior to } \\
\text { surgery? }\end{array}$ & $\begin{array}{l}\text { Recommenda- } \\
\text { tions for } \\
\text { infertile } \\
\text { patients? }\end{array}$ & $\begin{array}{l}\text { Recommenda- } \\
\text { tions on } \\
\text { fertility } \\
\text { preservation? }\end{array}$ & $\begin{array}{l}\text { Surgery prior to } \\
\text { IVF? }\end{array}$ \\
\hline $\begin{array}{l}\text { Spain: } \\
\text { Endometriosis, } \\
\text { women } \\
\text { of childbearing } \\
\text { age [49] }\end{array}$ & 2018 & SEF & Yes & Yes & Yes & $\begin{array}{l}\text { Only in case of } \\
\text { rapid growth or } \\
\text { pain }\end{array}$ \\
\hline $\begin{array}{l}\text { UK: } \\
\text { Endometriosis } \\
\text { [50] }\end{array}$ & 2017 & NICE & Yes & Yes & No & No \\
\hline $\begin{array}{l}\text { Lessey 2018: } \\
\text { Ovarian } \\
\text { endometriosis \& } \\
\text { infertility [26] }\end{array}$ & 2018 & $\begin{array}{l}\text { Publication/ } \\
\text { debate }\end{array}$ & yes & Yes & Yes & $\begin{array}{l}\text { Only } 1 / 5 \\
\text { discussants } \\
\text { recommended } \\
\text { FP }\end{array}$ \\
\hline $\begin{array}{l}\text { Cosma 2020: } \\
\text { Classification of } \\
\text { endometriosis } \\
\text { [51] }\end{array}$ & 2020 & Review & Yes & Yes & Yes & $\begin{array}{l}\text { Only in } \\
\text { symptomatic } \\
\text { patients and } \\
\text { abnormal } \\
\text { fertility tests }\end{array}$ \\
\hline $\begin{array}{l}\text { Miller 2020: } \\
\text { Endometrioma } \\
\text { and fertility [8] }\end{array}$ & 2020 & $\begin{array}{l}\text { Systematic } \\
\text { review }\end{array}$ & Yes & No & Yes & Yes \\
\hline
\end{tabular}

ACOG, American College of Obstetricians and Gynecologists; AWMF, Arbeitsgemeinschaft der Wissenschaftlichen Medizinischen Fachgesellschaften (Association of the Scientific Medical Societies); CNGOF, Collège National des Gynécologues et Obstétricien Français; DGGG, Deutsche Gesellschaft für Gynäkologie und Geburtshilfe (German Society of Gynecology and Obstetrics ); ESHRE, European Society of Human Reproduction and Embryology; FertiPROTEKT, Network of fertility preservation centres in German-speaking countries; FIGO, International Federation Of Gynecology And Obstetrics; FP, fertility preservation; NICE, (United Kingdom) National Institute for Health and Care Excellence; IVF, in vitro fertilization; SEF, Sociedad Española de Fertilidad (Spanish Fertility Society); SIGO, Italian Society of Gynecology and Obstetrics; SOGC, Society of Obstetricians and Gynaecologists of Canada; WES, World Endometriosis Society.

During the survey, we also decided to review the literature for potential algorithms on fertility preservation and endometriosis. Five proposed algorithms for fertility preservation and endometriosis were identified in the recent literature (Table 2) $[8,47,51-53]$. While the publication of such recommendations is to be welcomed, their approach is heterogeneous, with selection criteria focussing variously on age, low AMH and the presence of endometriomas. Cosma et al. (2020) do not implement cryopreservation as a routine strategy in their algorithm, but state that it can be an option in selected cases with previous ovarian surgery or low AMH (near $1 \mathrm{ng} / \mathrm{ml}$ ) [51]. The algorithm of Kho et al. (2018) looks at AMH and AFC when endometriosis is associated with concomitant fertility problems [52]; when poor ovarian reserve is encountered in women $>30$ years of age, gamete preservation is offered before surgical treatment. von Wolff \& Nawroth (2020) only recommend cryopreservation in women with high ovarian reserve (AMH $>1 \mathrm{ng} / \mathrm{ml}$ ) and guide women with low reserve directly to ART [47]. Miller (2020) addresses the negative impact on ovarian function subsequent to surgery; cryopreservation is proposed as an option in the case of endometriomas 
larger than $3 \mathrm{~cm}$ [8]. Most recently, Dolmans \& Donnez (2021) have discussed the strategy of ovarian tissue cryopreservation as an alternative to oocyte vitrification for fertility preservation in endometriosis, examining the indications and results of both options, and advise the use of ovarian tissue cryopreservation in all stage III and IV endometriosis patients where surgery is needed, $\mathrm{AMH}$ is low and the patient older than 30 years [53].

Table 2

Published algorithms for the management of fertility preservation in women with endometriosis.

\begin{tabular}{|lll|}
\hline Publication & Year & Source \\
\hline Kho RM, et al [52] & 2018 & Summary of society guidelines \\
\hline Von Wolff M \& Nawroth F [47] & 2020 & FertiPROTEKT \\
\hline Miller E [8] & 2020 & Systematic review \\
\hline Cosma S \& Benedetto C [51] & 2020 & Publication \\
\hline Dolmans MM \& Donnez J [53] & 2021 & Review and opinion paper \\
\hline
\end{tabular}

With reference to these different algorithms, we distilled a proposed Europe-wide consensus algorithm to address the results of the survey (Figure 4) and in the author's opinion it may help to harmonize the available ones. An algorithm should cover the patients at risk and thus we constructed it so that patients with higher risk for fertility problems have higher access to fertility preservation. As AFC is a more subjective measure, we did not include this in the algorithm, although some fertility specialists may continue to use AFC to assess ovarian reserve and, with experience, it can be cost-effective and equal to $\mathrm{AMH}$. Age is an important parameter as some countries restrict access to ART above a certain age. As 'young' oocytes are of better quality with consequently higher rates of maturity, fertilisation and good quality blastocysts, it is important to stress that fertility preservation should be accessible also for younger women for improving live birth rate. Preservation of fertility in older women with endometriosis tends to be less successful and will result in increased costs of ART $[54,55]$.

As a result of undertaking this survey and constructing a uniform algorithm, we believe that fertility outcomes for women with endometriosis can be improved. It must be recognised that the priority in endometriosis patients, regardless of age and stage, is to control progression of the disease (usually with medical treatment), without resorting to surgery that could reduce antral follicles. Patients should be informed of the influence of age on reproduction (encouraging the patient not to postpone pregnancy excessively) and their ovarian reserve. While quantifying antral follicles might be difficult in the context of an existing endometrioma, AMH determination is a good additional marker of follicular density [22]. Patients with endometriomas that require surgery should be informed of the risk that surgery imparts on their ovarian reserve, and that it would be appropriate to assess the need and possibility of performing follicular cell preservation before or after surgery. As ART and fertility preservation are not covered by health insurances in all European countries, this might have an impact on deciding for or against fertility preservation to postpone motherhood.

The likely uptake of this proposal for fertility preservation in endometriosis based on a European survey and current literature is uncertain. No internationally recognised guidelines (i.e. ESHRE or ASRM) - which are important for disseminating and encouraging uptake of new developments in reproductive medicine - currently exist for fertility preservation with a focus on and clear recommendations for endometriosis patients. However, it should be 
appreciated that as early as 2015 , endometriosis was already recognised as a potential indication for fertility preservation. A 20-person expert working group of ESHRE and ASRM highlighted the need to discuss and offer fertility preservation to patients with benign diseases causing premature ovarian insufficiency including autoimmune diseases (e.g. systemic lupus erythematosus, inflammatory bowel diseases, rheumatoid arthritis) and gynaecological conditions, including endometriosis [56]. The advice for fertility preservation in endometriosis has been repeated in more recent publications [1], but there remain no clear guidelines from the leading international specialist societies for its implementation in daily practice.

At the time this manuscript was submitted, following standard procedures for updating the ESHRE guidelines, a draft was available in which to collect feedback from different stakeholders. In the draft available on 5 July 2021, it was stated that "In case of extensive ovarian endometriosis, clinicians should discuss the pros and cons of fertility preservation with women with endometriosis. The true benefit of fertility preservation in women with endometriosis remains unknown." The statement was given a strong recommendation. The fertility problems with regard to endometriosis are however well known. More education and better awareness among healthcare professionals involved in managing women with endometriosis could facilitate counselling of patients on the risks of infertility and the available options for fertility preservation options. This can however be frustrated by unclear local legislation which can limit access to adequate support. The differences across Europe are large and, as the contradictory responses within the same country have shown, a lot of work will be required to address these inequalities. The support of European (e.g. European Society of Gynaecology (ESG), ESHRE, the FertiPROTEKT Network-and others) and local medical societies can play an important role by influencing legislators and creating awareness among gynaecologists, reproductive medicine specialists and patients.

Reimbursement for fertility preservation does not depend on guidelines. As it is clear from this survey a huge discrepancy exists across Europe. However, the potential loss of fertility, especially in the case of advanced endometriosis (stage III or IV) or after surgery is well known. There are clear, published recommendations detailing the effectiveness of different options for fertility preservation that could be offered to those patients [53, 57]. For example, compared to the management of women with oncological pathology, ovarian tissue cortex explantation plays a minor role in cryopreservation for women with endometriosis. This may be due to the perception in some countries that this technique is experimental, although the latest ASRM guidelines now endorse this procedure as an acceptable fertility preservation method [22]. With more than 200 live births reported, this technique certainly credits a place for fertility preservation [53]. Of course, medical criteria and individual circumstances will play a role on deciding which procedure is best suited for each patient. Therefore, the decision to preserve fertility in this type of patients deserves clear recommendations.

\section{Conclusions}

The results of this survey of 58 European gynaecological surgeons and reproductive medicine specialists show a lack of uniformity in guidelines and practices to preserve fertility in women with endometriosis. Some aspects of endometriosis and fertility already show a good uptake, such as reduction of endometriomas before oocyte pick-up, but the availability of an endoscopic surgeon may be a limiting factor for some fertility centres.

Large differences in fertility preservation strategies across Europe can be caused by multiple factors such as lack of access to surgery or fertility centres, lack of knowledge, unfamiliarity with procedures, absent or unclear regulations, or confusing guidelines. However, counselling for fertility preservation is becoming more relevant to endometriosis patients to maximise their chances of becoming pregnant and having a healthy baby during their reproductive life. The women's age, stage of the disease, and previous surgical treatments may all result in a compromised ovarian 
reserve. Even in the absence of surgical intervention, ovarian reserve will still be negatively impacted over time. The intervention of European societies to create awareness and educate women and healthcare professionals is urgently needed, considering incidence, pathology, and surgical consequences of endometriosis.

\section{Abbreviations}

ACOG American College of Obstetricians and Gynecologists

AFC Antral follicular count

AMH Anti-Müllerian hormone

ART Assisted reproductive techniques

ASRM American Society for Reproductive Medicine

AWMF Arbeitsgemeinschaft der Wissenschaftlichen Medizinischen Fachgesellschaften

CNGOF Collège National des Gynécologues et Obstétricien Français

DGGG Deutsche Gesellschaft für Gynäkologie und Geburtshilfe

ESHRE European Society of Human Reproduction and Embryology

FertiPROTEKT Network of fertility preservation centres in German-speaking countries

FIGO International Federation Of Gynecology And Obstetrics

FP fertility preservation

FSH Follicle-stimulating hormone

$\mathrm{GnRH} \quad$ Gonadotropin-releasing hormone

IVF In-vitro fertilization

NICE National Institute for Health and Care

SEF Sociedad Española de Fertilidad

SIGO Italian Society of Gynecology and Obstetrics

SOGC Society of Obstetricians and Gynaecologists of Canada

WES World Endometriosis Society.

\section{Declarations}

\section{Ethics approval and consent to participate}

Not applicable. 


\section{Consent for publication}

Not applicable.

\section{Availability of data and materials}

This was not an interventional study and no new patient data were created or analysed. Data sharing is not applicable to this article.

\section{Competing interests}

MM is employed by the funder of this survey, PregLem S.A., and contributed to the design of the survey and reviewed the manuscript. The other authors declare no conflicts of interest.

\section{Funding}

The survey platform was funded by PregLem (PregLem SA, Route de Frontenex 41A, 1207 Geneva, Switzerland) [a member of the Gedeon Richter group, Budapest, Hungary] and dispersed through the ORBIS-network across Europe.

\section{Authors' contributions}

N.S. and J.V. conceived of the presented idea, developed the survey and performed the computations. N.S. and M.M. verified the analytical methods. All authors helped to shape the research, disseminate the survey and contributed to the analysis and interpretation of the results. N.S. took the lead in writing the manuscript and all authors provided critical feedback and contributed to the final manuscript. All authors have read and agreed to the published version of the manuscript.

\section{Acknowledgements}

Editorial support and assistance in the preparation of figures was provided by Joanne Fitz-Gerald and Jonathan A C Lee at FourWave Medical Communications, the funding for which was provided by PregLem S.A./Gedeon Richter.

\section{References}

1. Donnez J, Dolmans MM. Fertility preservation in women. N Engl J Med. 2017;377:1657-65. doi:10.1056/NEJMra1614676.

2. Rienzi L, Gracia C, Maggiulli R, LaBarbera AR, Kaser DJ, Ubaldi FM, Vanderpoel S, Racowsky C. Oocyte, embryo and blastocyst cryopreservation in ART: systematic review and meta-analysis comparing slow-freezing versus vitrification to produce evidence for the development of global guidance. Hum Reprod Update. 2017;23:139-55. doi:10.1093/humupd/dmw038.

3. Cobo A, Garcia-Velasco J, Domingo J, Pellicer A, Remohi J. Elective and onco-fertility preservation: factors related to IVF outcomes. Hum Reprod. 2018;33:2222-31. doi:10.1093/humrep/dey321.

4. Somigliana E, Vigano P, Filippi F, Papaleo E, Benaglia L, Candiani M, Vercellini P. Fertility preservation in women with endometriosis: for all, for some, for none? Hum Reprod. 2015;30:1280-6. doi:10.1093/humrep/dev078.

5. Horton J, Sterrenburg M, Lane S, Maheshwari A, Li TC, Cheong Y. Reproductive, obstetric, and perinatal outcomes of women with adenomyosis and endometriosis: a systematic review and meta-analysis. Hum Reprod Update. 2019;25:592-632. doi:10.1093/humupd/dmz012. 
6. Llarena NC, Falcone T, Flyckt RL. Fertility preservation in women with endometriosis. Clin Med Insights Reprod Health. 2019;13:1179558119873386. doi:10.1177/1179558119873386.

7. Tanbo T, Fedorcsak P. Endometriosis-associated infertility: aspects of pathophysiological mechanisms and treatment options. Acta Obstet Gynecol Scand. 2017;96:659-67. doi:10.1111/aogs.13082.

8. Miller CE. The endometrioma treatment paradigm when fertility is desired: a systematic review. J Minim Invasive Gynecol. 2021;28:575-86. doi:10.1016/j.jmig.2020.11.020.

9. Kitajima M, Defrère S, Dolmans MM, Colette S, Squifflet J, Van Langendonckt A, Donnez J. Endometriomas as a possible cause of reduced ovarian reserve in women with endometriosis. Fertil Steril. 2011;96:685-91. doi:10.1016/j.fertnstert.2011.06.064.

10. Kitajima M, Dolmans MM, Donnez O, Masuzaki H, Soares M, Donnez J. Enhanced follicular recruitment and atresia in cortex derived from ovaries with endometriomas. Fertil Steril. 2014;101:1031-7. doi:10.1016/j.fertnstert.2013.12.049.

11. Kitajima M, Khan KN, Harada A, Taniguchi K, Inoue T, Kaneuchi M, Miura K, Masuzaki H. Association between ovarian endometrioma and ovarian reserve. Front Biosci (Elite Ed). 2018;10:92-102. doi:10.2741/e810.

12. Bourdon M, Raad J, Dahan Y, Marcellin L, Maignien C, Even M, Pocate-Cheriet K, Lamau MC, Santulli P, Chapron C. Endometriosis and ART: A prior history of surgery for OMA is associated with a poor ovarian response to hyperstimulation. PLoS One. 2018;13:e0202399. doi:10.1371/journal.pone.0202399.

13. Liang Y, Yang X, Lan Y, Lei L, Li Y, Wang S. Effect of endometrioma cystectomy on cytokines of follicular fluid and IVF outcomes. J Ovarian Res. 2019;12:98. doi:10.1186/s13048-019-0572-7.

14. Biacchiardi CP, Piane LD, Camanni M, Deltetto F, Delpiano EM, Marchino GL, Gennarelli G, Revelli A. Laparoscopic stripping of endometriomas negatively affects ovarian follicular reserve even if performed by experienced surgeons. Reprod Biomed Online. 2011;23:740-6. doi:10.1016/j.rbmo.2011.07.014.

15. Calagna G, Della Corte L, Giampaolino P, Maranto M, Perino A. Endometriosis and strategies of fertility preservation: a systematic review of the literature. Eur J Obstet Gynecol Reprod Biol. 2020;254:218-25. doi:10.1016/j.ejogrb.2020.09.045.

16. Karadağ C, Yoldemir T, Demircan Karadağ S, Turgut A. The effects of endometrioma size and bilaterality on ovarian reserve. J Obstet Gynaecol. 2020;40:531-6. doi:10.1080/01443615.2019.1633518.

17. Somigliana E, Arnoldi M, Benaglia L, lemmello R, Nicolosi AE, Ragni G. IVF-ICSI outcome in women operated on for bilateral endometriomas. Hum Reprod. 2008;23:1526-30. doi:10.1093/humrep/den133.

18. Cranney R, Condous G, Reid S. An update on the diagnosis, surgical management, and fertility outcomes for women with endometrioma. Acta Obstet Gynecol Scand. 2017;96:633-43. doi:10.1111/aogs.13114.

19. Cobo A, Diaz C. Clinical application of oocyte vitrification: a systematic review and meta-analysis of randomized controlled trials. Fertil Steril. 2011;96:277-85. doi:10.1016/j.fertnstert.2011.06.030.

20. Cobo A, Coello A, de Los Santos MJ, Giles J, Pellicer A, Remohí J, García-Velasco JA. Number needed to freeze: cumulative live birth rate after fertility preservation in women with endometriosis. Reprod Biomed Online. 2021;42:725-32. doi:10.1016/j.rbmo.2020.12.013.

21. Donnez J, Dolmans MM, Demylle D, Jadoul P, Pirard C, Squifflet J, Martinez-Madrid B, van Langendonckt A. Livebirth after orthotopic transplantation of cryopreserved ovarian tissue. Lancet. 2004;364:1405-10. doi:10.1016/s0140-6736(04)17222-x.

22. Practice Committee of the American Society for Reproductive Medicine (ASRM). Fertility preservation in patients undergoing gonadotoxic therapy or gonadectomy: a committee opinion. Fertil Steril. 2019;112:1022-33. doi:10.1016/j.fertnstert.2019.09.013. 
23. Dong Z, An J, Xie X, Wang Z, Sun P. Preoperative serum anti-Müllerian hormone level is a potential predictor of ovarian endometrioma severity and postoperative fertility. Eur J Obstet Gynecol Reprod Biol. 2019;240:113-20. doi:10.1016/j.ejogrb.2019.06.024.

24. Cobo A, Giles J, Paolelli S, Pellicer A, Remohí J, García-Velasco JA. Oocyte vitrification for fertility preservation in women with endometriosis: an observational study. Fertil Steril. 2020;113:836-44.

doi:10.1016/j.fertnstert.2019.11.017.

25. Cobo A, García-Velasco JA, Remohí J, Pellicer A. Oocyte vitrification for fertility preservation for both medical and nonmedical reasons. Fertil Steril. 2021;115:1091-101. doi:10.1016/j.fertnstert.2021.02.006.

26. Lessey BA, Gordts S, Donnez O, Somigliana E, Chapron C, Garcia-Velasco JA, Donnez J. Ovarian endometriosis and infertility: in vitro fertilization (IVF) or surgery as the first approach? Fertil Steril. 2018;110:1218-26. doi:10.1016/j.fertnstert.2018.10.003.

27. Hirsch M, Begum MR, Paniz É, Barker C, Davis CJ, Duffy J. Diagnosis and management of endometriosis: a systematic review of international and national guidelines. BJOG. 2018;125:556-64. doi:10.1111/14710528.14838.

28. Kuroda K, Ikemoto Y, Ochiai A, Ozaki R, Matsumura Y, Nojiri S, Nakagawa K, Sugiyama R. Combination treatment of preoperative embryo cryopreservation and endoscopic surgery (surgery-ART hybrid therapy) in infertile women with diminished ovarian reserve and uterine myomas or ovarian endometriomas. J Minim Invasive Gynecol. 2019;26:1369-75. doi:10.1016/j.jmig.2019.02.008.

29. Dadoun Y, Azaïs H, Keller L, d'Orazio E, Collinet P, Decanter C. [Systematic proposal of fertility preservation by mature oocyte cryopreservation for recurrent benign ovarian tumors]. Gynecol Obstet Fertil Senol. 2017;45:35965. doi:10.1016/j.gofs.2017.03.005.

30. Decanter C, d'Argent EM, Boujenah J, Poncelet C, Chauffour C, Collinet P, Santulli P. [Endometriosis and fertility preservation: CNGOF-HAS Endometriosis Guidelines]. Gynecol Obstet Fertil Senol. 2018;46:368-72. doi:10.1016/j.gofs.2018.02.010.

31. Haydardedeoglu B, Zeyneloglu HB. The impact of endometriosis on fertility. Womens Health (Lond). 2015;11:619-23. doi:10.2217/whe.15.48.

32. Björk E, Gustavsson M, Palmstierna M, Valentin A, Olovsson M, Melin AS [Endometriosis - new clinical guidelines for better and equal care in Sweden]. Lakartidningen 2020, 117.

33. Nnoaham KE, Hummelshoj L, Webster P, d'Hooghe T, de Cicco Nardone F, de Cicco Nardone C, Jenkinson C, Kennedy SH, Zondervan KT. Impact of endometriosis on quality of life and work productivity: a multicenter study across ten countries. Fertil Steril. 2011;96:366-73.e368. doi:10.1016/j.fertnstert.2011.05.090.

34. Evans MB, Decherney AH. Fertility and endometriosis. Clin Obstet Gynecol. 2017;60:497-502. doi:10.1097/grf.0000000000000295.

35. Lebovic DI, Mueller MD, Taylor RN. Immunobiology of endometriosis. Fertil Steril. 2001;75:1-10. doi:10.1016/s0015-0282(00)01630-7.

36. Kao LC, Germeyer A, Tulac S, Lobo S, Yang JP, Taylor RN, Osteen K, Lessey BA, Giudice LC. Expression profiling of endometrium from women with endometriosis reveals candidate genes for disease-based implantation failure and infertility. Endocrinology. 2003;144:2870-81. doi:10.1210/en.2003-0043.

37. Marie-Madeleine D, Camille H, Luciana C, Glenn S. Summary of the ISFP congress, New York, 14-16 November, 2019. J Assist Reprod Genet. 2020;37:983-5. doi:10.1007/s10815-020-01757-y.

38. American College of Obstetricians and Gynecologists (ACOG). Practice bulletin no. 114: management of endometriosis. Obstet Gynecol. 2010;116:223-36. doi:10.1097/AOG.0b013e3181e8b073. 
39. Leyland N, Casper R, Laberge P, Singh SS. Endometriosis: diagnosis and management. J Obstet Gynaecol Can. 2010;32:1-32.

40. Dunselman GA, Vermeulen N, Becker C, Calhaz-Jorge C, D'Hooghe T, De Bie B, Heikinheimo O, Horne AW, Kiesel L, Nap A, et al. ESHRE guideline: management of women with endometriosis. Hum Reprod. 2014;29:400-12. doi:10.1093/humrep/det457.

41. Anderson RA, Amant F, Braat D, D'Angelo A, Chuva deS, Lopes SM, Demeestere I, Dwek S, Frith L, Lambertini M, Maslin C, et al. ESHRE guideline: female fertility preservation. Hum Reprod Open 2020, 2020, hoaa052, doi:10.1093/hropen/hoaa052.

42. Adamson GD, Endometriosis. Medical and Surgical Management of Pain and Infertility. Available online: https://www.figo.org/sites/default/files/2020-07/Endometriosis\%20Slides\%202016\%20-\%20Rep\%20Med.pdf (accessed on 5 March 2021).

43. Johnson NP, Hummelshoj L, Adamson GD, Keckstein J, Taylor HS, Abrao MS, Bush D, Kiesel L, Tamimi R, SharpeTimms KL, et al. World Endometriosis Society consensus on the classification of endometriosis. Hum Reprod. 2017;32:315-24. doi:10.1093/humrep/dew293.

44. Collinet P, Fritel X, Revel-Delhom C, Ballester M, Bolze PA, Borghese B, Bornsztein N, Boujenah J, Brillac T, Chabbert-Buffet N, et al. Management of endometriosis: CNGOF/HAS clinical practice guidelines - Short version. J Gynecol Obstet Hum Reprod. 2018;47:265-74. doi:10.1016/j.jogoh.2018.06.003.

45. AWMF Arbeitsgemeinschaft der Wissenschaftlichen Medizinischen Fachgesellschaften. Leitlinie Diagnostik und Therapie der Endometriose [German guideline for diagnosis and management of endometriosis]. Available online: https://www.awmf.org/leitlinien/awmf-regelwerk (accessed on 5 March 2021).

46. AWMF Arbeitsgemeinschaft der Wissenschaftlichen Medizinischen Fachgesellschaften. Leitlinie Fertilitätserhalt [German guideline for fertility preservation]. Available online: https://www.awmf.org/leitlinien/awmf-regelwerk (accessed on 5 March 2021).

47. von Wolff M, Nawroth F Fertility Preservation in Oncological and Non-Oncological Diseases: A Practical Guide, 1st ed.; Springer: 2020.

48. SIGO Società Italiana di Ginecologia e Obstetrica. Diagnosi e Trattamento dell'Endometriosi [Diagnosis and Treatment of Endometriosis]. June 2018. Available online: https://www.aogoi.it/media/5066/lg_diagnositrattamentoendometriosi-2018.pdf (accessed on 5 March 2021).

49. SEF Sociedad Española de Fertilidad. Manejo de la paciente con endometriosis durante la edad fértil [Management of endometriosis in women of childbearing age]. Available online: https://www.sefertilidad.net/docs/biblioteca/manejoEndometriosis.pdf (accessed on 5 March 2021).

50. NICE. National Institute for Health and Care Excellence. Endometriosis: diagnosis and management. NICE guideline (NG73). Available online: https://www.nice.org.uk/guidance/ng73/resources/endometriosis-diagnosisand-management-pdf-1837632548293 and https://www.nice.org.uk/guidance/NG73 (accessed on 5 March 2020).

51. Cosma S, Benedetto C. Classification algorithm of patients with endometriosis: proposal for tailored management. Adv Clin Exp Med. 2020;29:615-22. doi:10.17219/acem/118849.

52. Kho RM, Andres MP, Borrelli GM, Neto JS, Zanluchi A, Abrão MS. Surgical treatment of different types of endometriosis: Comparison of major society guidelines and preferred clinical algorithms. Best Pract Res Clin Obstet Gynaecol. 2018;51:102-10. doi:10.1016/j.bpobgyn.2018.01.020.

53. Dolmans MM, Donnez J. Fertility preservation in women for medical and social reasons: Oocytes vs ovarian tissue. Best Pract Res Clin Obstet Gynaecol. 2021;70:63-80. doi:10.1016/j.bpobgyn.2020.06.011. 
54. Dolmans MM, Manavella DD. Recent advances in fertility preservation. J Obstet Gynaecol Res. 2019;45:266-79. doi:10.1111/jog.13818.

55. Cobo A, García-Velasco JA, Coello A, Domingo J, Pellicer A, Remohí J. Oocyte vitrification as an efficient option for elective fertility preservation. Fertil Steril. 2016;105:755-64.e758. doi:10.1016/j.fertnstert.2015.11.027.

56. Martinez F. Update on fertility preservation from the Barcelona International Society for Fertility PreservationESHRE-ASRM 2015 expert meeting: indications, results and future perspectives. Hum Reprod. 2017;32:1802-11. doi:10.1093/humrep/dex218.

57. Barnett R, Banks N, Decherney AH. Endometriosis and fertility preservation. Clin Obstet Gynecol. 2017;60:51723. doi:10.1097/grf.0000000000000311.

\section{Figures}

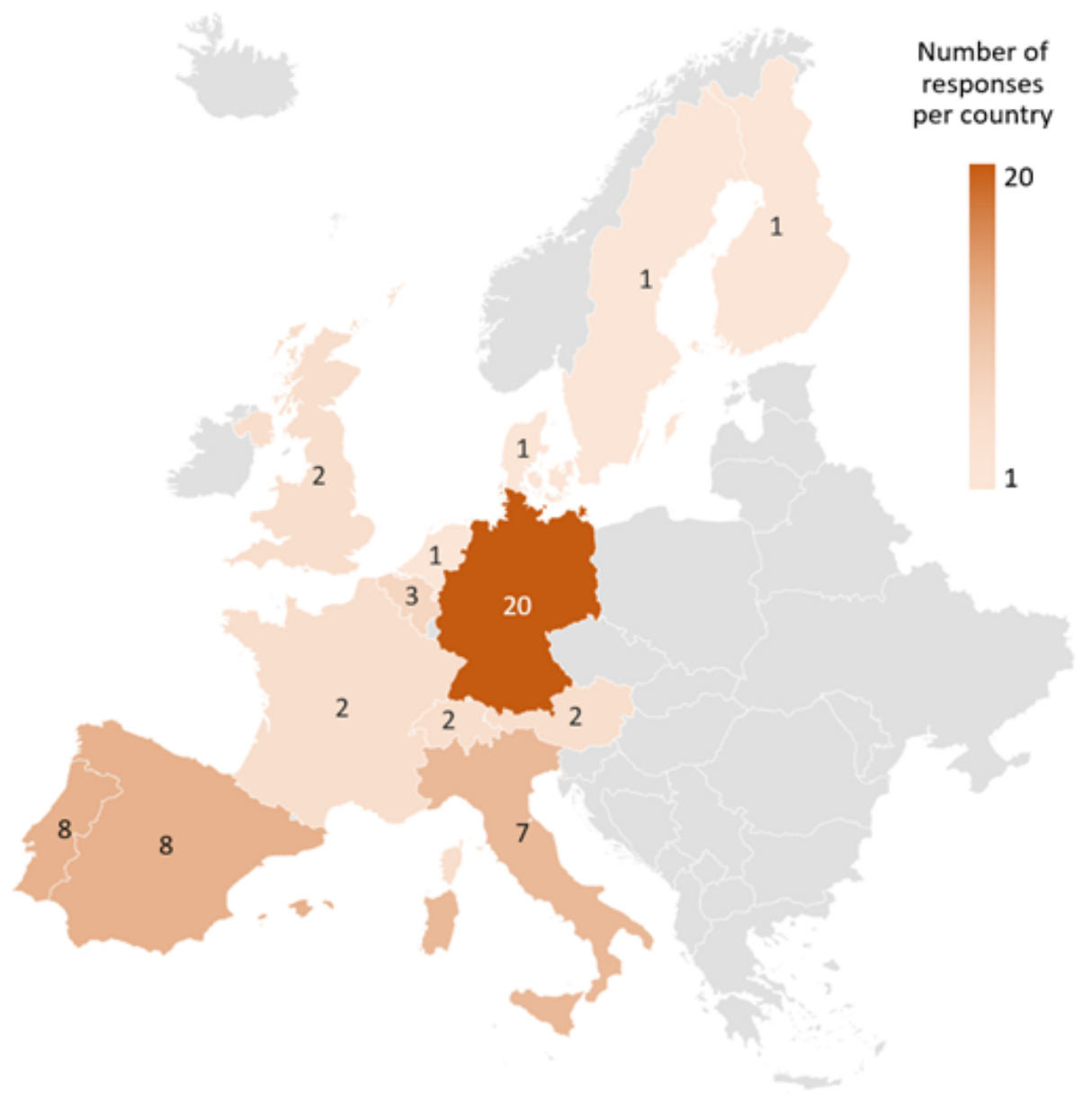

Figure 1

Participating centres by country. 
Responses by centre $(\mathrm{N}-58)$

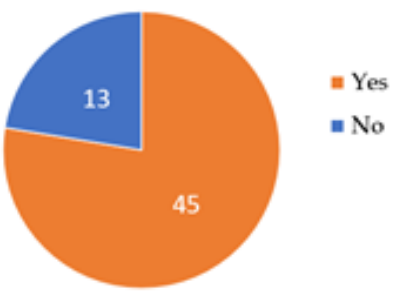

Responses by country $(\mathrm{N}-13)$

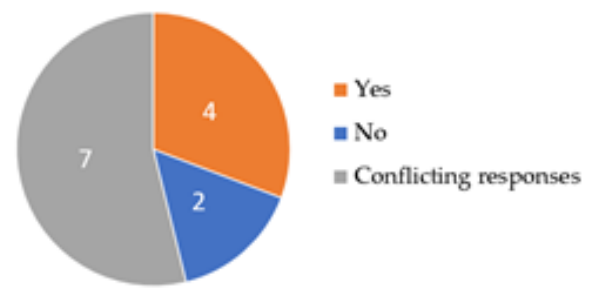

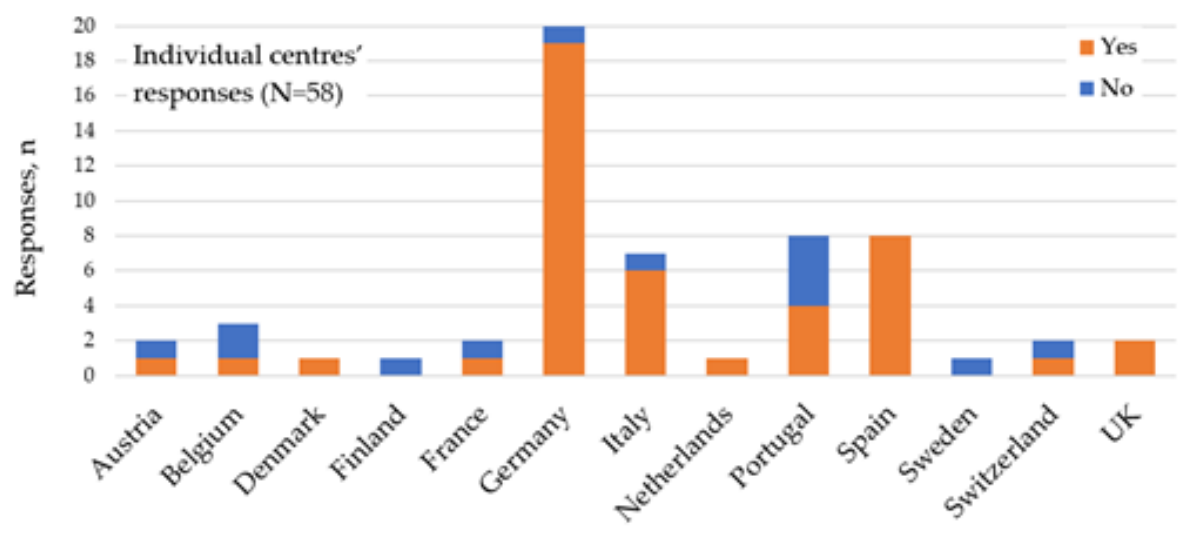

Figure 2

Does a national endometriosis guideline exist in your country?
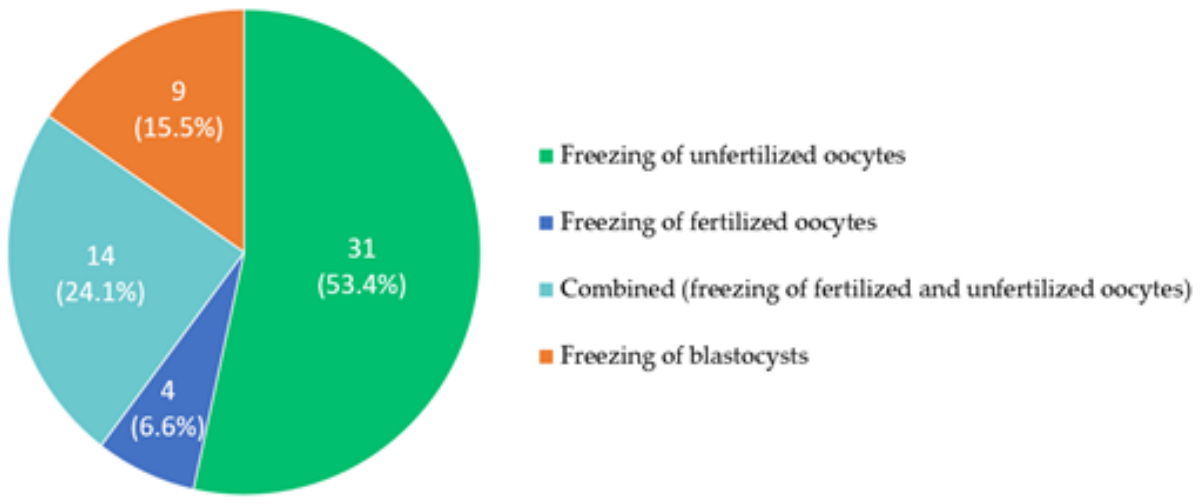

\section{Figure 3}

If fertility preservation is suggested to patients (with a partner) with endometriosis, what is the method performed in your clinic? (Responses by centre, $\mathrm{N}=58$ ). 


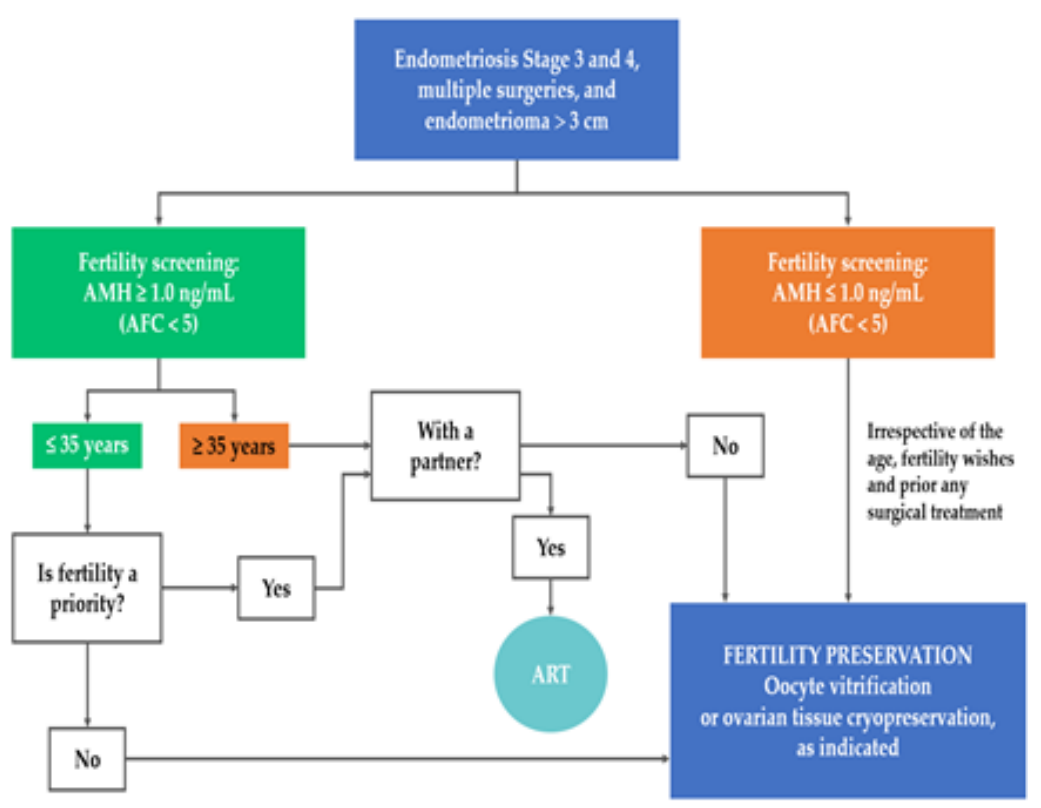

Figure 4

Proposed algorithm for the management of fertility preservation in women with endometriosis. AFC, antral follicular count; AMH, anti-Müllerian hormone.

\section{Supplementary Files}

This is a list of supplementary files associated with this preprint. Click to download.

- SupplementaryMaterials.docx 